\title{
Diminuição do sangramento pós- operatório produzido pela heparina, após aplicação tópica de adenosina trifosfato (ATP) em cirurgia cardíaca com circulação extracorpórea
}

\author{
Hermínio VEGA*, Helena NADER ${ }^{*}$, Carl P. DIETRICH*, Ênio BUFFOLO*
}

\begin{abstract}
VEGA, H.; NADER, H.; DIETRICH, C. P.; BUFFOLO, E. - Diminuição do sangramento pós-operatório produzido pela heparina, após aplicaçäo tópica de adenosina trifosfato (ATP) em cirúrgia cardiaca com circulaçāo extracorpórea. Rev. Bras. Cir. Cardiovasc., 8 (2):91-96, 1993.
\end{abstract}

RESUMO: A concentração de heparina doi determinada no sangue de pacientes submetidos a cirurgia cardíaca com circulação extracorpórea, antes e depois da sua neutralização com protamina. Determinouse também a quantidade de heparina no sangue coletado dos drenos da cavidade torácica 12 horas após a operação. Cerca de $15 \%$ da heparina, a despeito de um tempo de coagulação normal, permanece na circulação após a administração de protamina, e também é encontrada no sangue coletado dos drenos da cavidade torácica. O peso molecular médio dessa heparina circulante, bem como da encontrada nos drenos torácicos, foi ao redor de $7 \mathrm{KiloDaltons} \mathrm{(KDa),} \mathrm{comparando} \mathrm{ao} \mathrm{de} 15 \mathrm{KDa}$ da heparina dosada no sangue antes da sua neutralização pela protamina. Graças a achados anteriores de que as heparinas de baixo peso molecular, responsáveis pelo sangramento da ferida operatória, podem ser neutralizadas por trifosfato de adenosina (ATP) ${ }^{4}$, a cavidade torácica de pacientes consecutivos e não selecionados, divididos em 3 grupos de 15 , foi lavada com diferentes concentrações, ou de ATP $\left(10^{-5}, 5 \times 10^{-4} \mathrm{M}\right)$ ou com protamina, ou, ainda, apenas com solução fisiológica (grupo controle). Observou-se uma curva dose-resposta linear entre a diminuição do sangramento com o aumento da dose da ATP utilizada. ATP, numa concentração de $10^{-4} \mathrm{M}$, diminuiu significativamente o volume de sangue drenado da cavidade torácica dos pacientes (média de $288 \pm 188 \mathrm{ml}$ ), quando comparado ao grupo que recebeu protamina (média de $496 \pm 210 \mathrm{ml}$ ), e ao grupo controle (média $564 \pm 288 \mathrm{ml})(p<0,05)$. ATP numa concentração de $5 \times 10^{-5} \mathrm{M}$ reduziu as perdas sangũineas a $370 \pm 155 \mathrm{ml}$ dos pacientes $(\mathrm{p}<0,08)$. A média de sangramento, no total dos pacientes que receberam ATP, foi de $314 \pm 170 \mathrm{ml}(p<0,08)$.

DESCRITORES: sangramento em cirurgia cardíaca.

\section{INTRODUÇÃO}

O excessivo sangramento das feridas operatórias constitui um dos maiores problemas encontrados nas operações com auxílio da circulação extracorpórea ${ }^{7}$, onde o uso da anticoagulação com heparina é inevitável. CRUZ ${ }^{1}$ demonstrou que o efeito anti-hemostático da heparina era independente de células do sangue como as plaquetas, e correlacionava-se a estruturas especiais do tecido lesado. Desse modo, quando a heparina era aplicada topicamente às feridas superficiais da pele de

Trabalho realizado na Escola Paulista de Medicina. São Paulo, SP, Brasil.

Apresentado ao $20^{\circ}$ Congresso Nacional de Cirurgia Cardiaca. Maceió, AL, 2 e 3 de abril, 1993.

Laureado com o "Prêmio Nacional de Cirurgia Cardíaca - 1993".

- Da Escola Paulista de Medicina.

Endereço para separatas: Hermínio Vega. Rua Borges Lagoa $783,5^{2}$ andar. 04038 , São Paulo, SP, Brasil. 
VEGA, H.; NADER, H.; DIETRICH, C.P.; BUFFOLO, E. - Diminuição do sangramento pós-operatório produzido pela heparina, após aplicaçāo tópica de adenosina trifosfato (ATP) em cirúrgia cardiaca com circulaçăo extracorpórea. Rev. Bras. Cir. Cardiovasc., 8 (2):91-96, 1993.

camundongos produzidas experimentalmente, houve um aumento do sangramento de pequenas veias e capilares ${ }^{2}$. Essa atividade anti-hemostática persistiu, mesmo após lavar-se exaustivamente as preparações com solução salina, sugerindo que a heparina se ligaria a receptores da ferida determinando um sangramento incontrolável.

Entre as diversas proteínas testadas para inibir a atividade anti-hemostática da heparina, por exemplo, plasma e proteínas séricas, trombomiosina e actina, somente a miosina desnaturada foi capaz de revertê-la.

Da mesma forma, dentre os fosfatos de nucleotídeos testados como UTP, ITP, GTP, AMP, somente $\circ$ ATP e o ADP foram capazes de deslocar a heparina residual ligada a receptor, revertendo sua atividade hemorrágica ${ }^{2}$. Estudos in vitro demonstraram que a heparina inibe competitivamente a hidrólise do ATP pela miosina ATPase ${ }^{2}$. Esses achados, se associados, sugerem que a heparina ligar-se-ia a uma molécula miosina-like das células musculares lisas, inibindo a contração dos vasos, promovendo, então, aumento do sangramento. Muitos estudos têm demonstrado que a heparina de baixo peso molecular não se correlaciona com atividade anticoagulante, mas como uma atividade hemorrágica, já que uma heparina de baixo peso molecular (PM 4500), desprovida de atividade anticoagulante, foi igualmente efetiva em promover sangramento $4,8,11$.

Esses resultados nos estimularam a testar se a aplicaçăo tópica de ATP diminuiria o sangramento normalmente presente em pacientes, logo após cirurgias com circulação extracorpórea. Já que a protamina não é capaz de neutralizar totalmente as heparinas de baixo peso molecular ${ }^{6}$ presentes nas preparações comerciais, dosamos a quantidade de heparina remanescente na circulação após a administração de protamina, bem como no sangue coletado dos drenos dos pacientes 12 horas após a operação.

\section{CASUÍSTICA E MÉTODOS}

\section{Pacientes e Procedimentos}

Quarenta e cinco pacientes de ambos os sexos (45 a 60 anos de idade) submetidos a revascularização do miocárdio com auxílio de circulação extracorpórea foram selecionados para esse estudo. Exames pré-operatórios para avaliar a coagulação foram realizados, e excluídos os pacientes cujos resultados encontravam-se foram dos limites da normalidade. Todos os pacientes foram submetidos a circulação extracorpórea com hipotermia moderada $\left(28^{\circ} \mathrm{C}\right)$. O circuito de circulação extracorpórea recebeu um volume de $2000 \mathrm{ml}$ de solução de Ringer com lactato como prime. Dez minutos antes da instituição do bypass cardiopulmonar, a anticoagulação sistêmica foi realizada com $4 \mathrm{mg} / \mathrm{kg}$ de heparina (Liquemine, Laboratórios Roche, São Paulo, Brasil). Doses adicionais de heparina foram administradas a cada hora, caso necessário, com base no tempo de coagulação ativado (TCA), que deveria ser mantido ao redor de 400 segundos, até o término da circulação extracorpórea. Ao término do bypass cardiopulmonar, sulfato de protamina (Laboratórios Roche, São Paulo, Brasil) na proporção de $1 \mathrm{mg}: 1 \mathrm{mg}$ de heparina residual determinada por uma curva dose-resposta previamente construida, foi administrado, por via sistêmica, até que os valores do TCA atingissem os valores normais (90-120 segundos). Imediatamente antes do seu fechamento, a cavidade torácica foi lavada com $500 \mathrm{ml}$ de solução fisiológica (no grupo controle), ou $500 \mathrm{ml}$ de solução fisiológica contendo $10^{-5}, 5 \times 10^{-4}$ de ATP (Striadyne, Wyeth, França), ou, ainda, $500 \mathrm{ml}$ de solução fisiológica com $100 \mathrm{mg}$ de protamina. As soluções eram mantidas na cavidade torácica cerca de 10 minutos. Após aspiração exaustiva do conteúdo e retirada de todo o líqüido das cavidades mediastinal e pleural com o auxílio de compressas, a cavidade era drenada ( 2 drenos) e fechada. 0 sangue foi coletado dos drenos que terminavam em 2 frascos contendo $200 \mathrm{ml}$ de solução salina, e os volumes coletados anotados a cada hora com intervalo de pelo menos 12 horas.

\section{Determinações da Heparina}

$20 \mu \mathrm{g}$ de sulfato de condroitina (usado como carreador) e 1,2 M de $\mathrm{NaCl}$ (concentração final) foram adicionados a:

- $10 \mathrm{ml}$ de sangue colhido dos pacientes, $10 \mathrm{mi}$ nutos após a injeção de heparina;

- $10 \mathrm{ml}$ de sangue colhido 10 minutos depois da infusão de protamina, para neutralização da heparina:

- $20 \mathrm{ml}$ do sangue colhido dos frascos de drenagem da cavidade torácica dos pacientes, 12 horas após a operação.

A cada uma dessas misturas era adicionado ácido tricloloroacético até uma concentração final de $10 \%$, que, então, era mantida refrigerada por 15 minutos. O precipitado formado era removido por centrifugação a $10.000 \mathrm{gpm}$ por 340 minutos. Dois volumes de metanol eram adicionados ao sobrenadante que, a seguir, era, então, mantido a $5^{\circ} \mathrm{C}$ durante o período de uma noite. O precipitado formado era coletado por centrifugação a $3.000 \mathrm{gpm}$ 
VEGA, H.; NADER, H.; DIETRICH, C.P.; BUFFOLO, E. - Diminuição do sangramento pós-operatório produzido pela heparina, após aplicação tópica de adenosina trifosfato (ATP) em cirúrgia cardíaca com circulaçāo extracorpórea. Rev. Bras. Cir. Cardiovasc., 8 (2):91-96, 1993.

por 15 minutos, seco e resuspenso em $100 \mu \mathrm{l}$ de água e analisado para a presença de heparina por eletroforese em gel de poliacrilamida e agarose como descrito anteriormente 3,10 .

\section{RESULTADOS}

Neutralização da Heparina Circulante em Pacientes Submetidos a Cirurgia Cardíaca

A Figura 1 mostra uma eletrosforese em gel de agarose e sua densitometria mostra a heparina presente no sangue antes e depois da administração da protamina, assim como a heparina presente no sangue coletado dos drenos torácicos. Torna-se claro que a protamina é incapaz de neutralizar toda a heparina circulante. A Tabela 1 mostra que apenas $85 \%$ da heparina presente no sangue dos pacientes foi neutralizada pelo sulfato de protamina; parte dos $15 \%$ restantes está, também, presente no sangue drenado no período de pós-operatório.

A Tabela 1 também demonstra que o TCA dos pacientes, após a administração de protamina, encontra-se dentro dos valores da normalidade. Isso implica que a heparina remanescente na circulação, após a infusão de protamina, não possui atividade

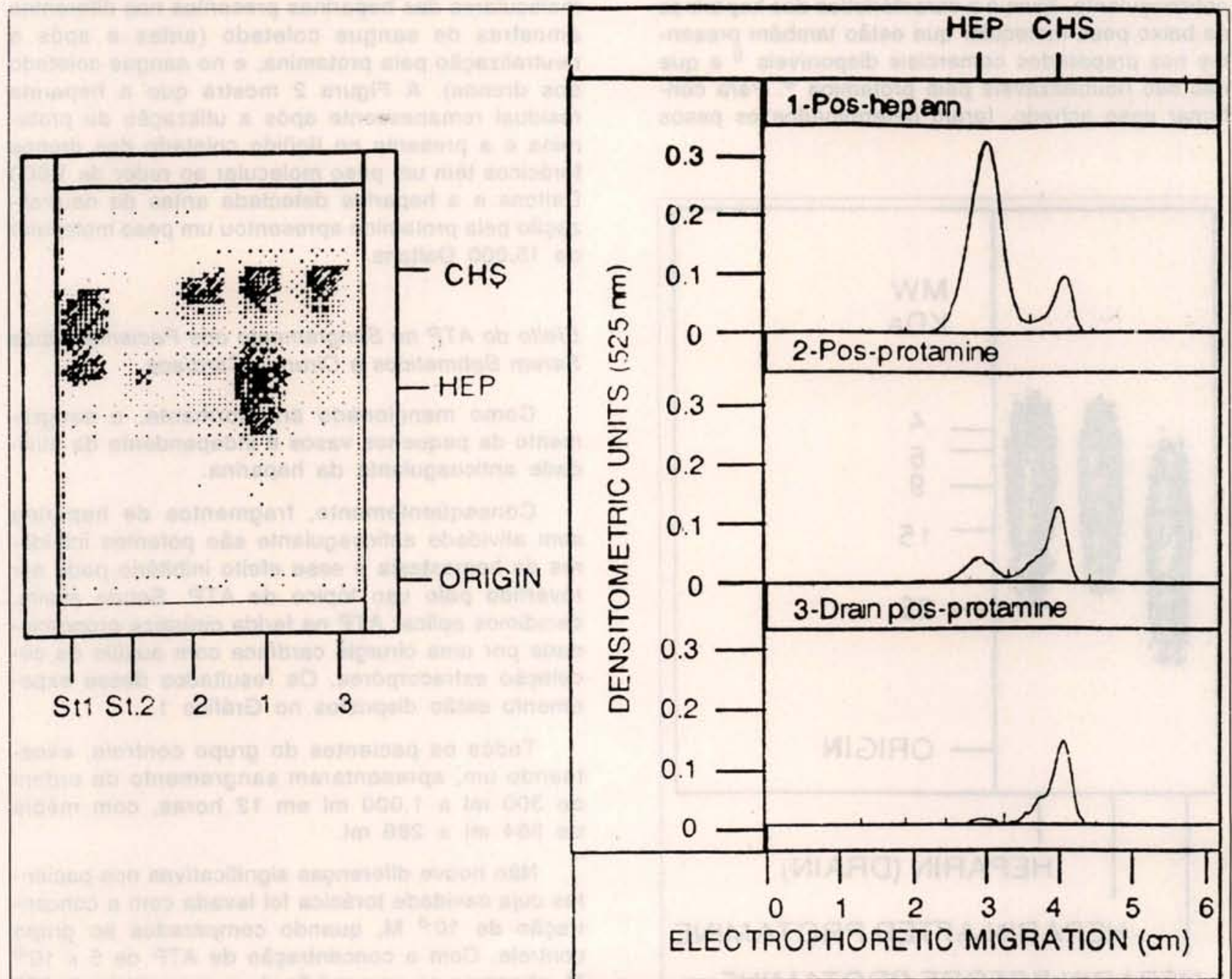

Fig. 1. Heparina dosada no sangue dos pacientes antes e após a neutralização com protamina. NaCl e sulfato de condroitina (usado como carreador para parte da recuperação da heparina) são adicionados a $10 \mathrm{ml}$ de sangue colhido do paciente 10 minutos após a administração de heparina 7; $10 \mathrm{ml}$ de sangue colhidos 10 minutos após a neutralização com protamina ${ }^{1}$ e a 20 ml do sangue colhido dos drenos torácicos ${ }^{2}$, até a obtenção de uma concentração final de $1,2 \mathrm{M}(\mathrm{NaCl})$ e $2 \mathrm{vg} / \mathrm{ml}$ (sulfato de condroitina. À mistura foi adicionado ácido tricloroacético até uma concentração final de $10 \%$. O precipitado formado após 15 minutos de refrigeração foi removido por centrifugação. Dois volumes de metanol foram adicionados ao sobrenadante, que foi mantido a $5^{\circ} \mathrm{C}$ pelo período de uma noite. $\mathrm{O}$ precipitado formado foi colhido por centrifugação, seco e ressuspenso em $100 \mathrm{ml}$ de água. Cinco aliquotas de 5 vl foram submetidas a eletroforese em gel de agarose, como já referido na secção MÉTODO (painel à esquerda). Após corar com azul de toluidina, as amostras de heparina e de sulfato de condroitina foram determinadas por densitometria (painel à direita). 
VEGA, H.; NADER, H.; DIETRICH, C. P.; BUFFOLO, E. - Diminuição do sangramento pós-operatório produzido pela heparina, após aplicação tópica de adenosina trifosfato (ATP) em cirúrgia cardiaca com circulação extracorpórea. Rev. Bras. Cir. Cardiovasc., 8 (2):91-96, 1993.

TABELA 1

NEUTRALIZAÇÃO DA HEPARINA COM PROTAMINA

\begin{tabular}{lcccc}
\hline PACIENTE & HEPARINA (UIIML) & & $\begin{array}{c}\text { TEMPODE COAGULAÇÃO } \\
\text { APÓSPROTAMINA } \\
\text { (SEGUNDOS) }\end{array}$ \\
\hline A.R. & POS-HEPARINA & PÓS-PROTAMINA & DRENOS & 130 \\
P.C. & 5,2 & 0,9 & 0,31 & 120 \\
M.J.S. & 7,3 & 1,2 & 0,25 & 90 \\
J.G. & 6,0 & 0,6 & 0,13 & 110 \\
I.L. & 8,0 & 1,2 & 0,25 & 90 \\
E.B. & 11,5 & 0,8 & 0,29 & 85 \\
J.R. & 17,6 & 0,9 & 0,19 & 94 \\
\hline
\end{tabular}

anticoagulante. Essa é a característica das heparinas de baixo peso molecular que estão também presentes nos preparados comerciais disponíveis ${ }^{9}$ e que não são neutralizáveis pela protamina ${ }^{6}$. Para confirmar esse achado, foram determinados os pesos

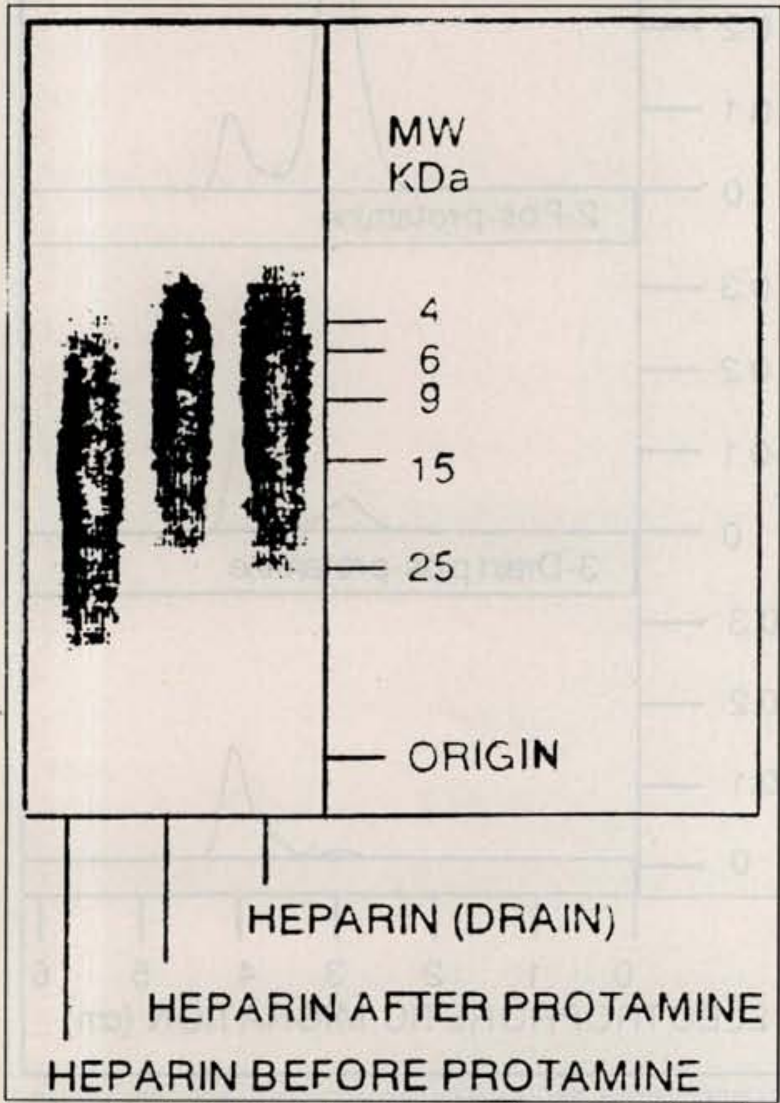

Fig. 2 - Peso molecular da heparina presente no sangue de pacientes antes e após a neutralização com protamina. Heparina foi retirada conforme descrito na Figura 1, exceto que sem o uso do carreador sulfato de condroitina. Aliquotas de $20 \mathrm{vl}$ das amostras indicadas na Figura foram aplicadas à placa com gel de poliacrilamida e submetidas a eletroforese, contra padrões de peso molecular e coradas por azul de toluidina, como referido na secção MÉTODO. moleculares das heparinas presentes nas diferentes amostras de sangue coletado (antes e após a neutralização pela protamina, e no sangue coletado dos drenos). A Figura 2 mostra que a heparina residual remanescente após a utilização de protamina e a presente no líqüido coletado dos drenos torácicos têm um peso molecular ao redor de 1.000 Daltons e a heparina detectada antes da neutralização pela protamina apresentou um peso molecular de 15.000 Daltons.

\section{Efeito do ATP no Sangramento dos Pacientes Após} Serem Submetidos a Cirurgia Cardíaca

Como mencionado anteriormente, o sangramento de pequenos vasos é independente da atividade anticoagulante da heparina.

Conseqüentemente, fragmentos de heparina sem atividade anticoagulante são potentes inibidores da hemostasia e esse efeito inibitório pode ser revertido pelo uso tópico de ATP. Sendo assim, decidimos aplicar ATP na ferida cirúrgica proporcionada por uma cirurgia cardíaca com auxílio da circulação extracorpórea. Os resultados desse experimento estão dispostos no Gráfico 1.

Todos os pacientes do grupo controle, excetuando um, apresentaram sangramento da ordem de $300 \mathrm{ml}$ a $1.000 \mathrm{ml}$ em 12 horas, com média de $564 \mathrm{ml} \pm 288 \mathrm{ml}$.

Não houve diferenças significativas nos pacientes cuja cavidade torácica foi lavada com a concentração de $10^{-5} \mathrm{M}$, quando comparados ao grupo controle. Com a concentração de ATP de $5 \times 10^{-5}$ $\mathrm{M}$, observou-se uma média de sangramento de 370 $\mathrm{ml} \pm 155 \mathrm{ml}$. Os melhores resultados foram obtidos com o grupo que recebeu ATP numa concentração de $10^{-4} \mathrm{M}$, cuja média foi de $288 \mathrm{ml} \pm 188 \mathrm{ml}$. O nível de significância (Teste $t$ ) entre o grupo controle e o que recebeu ATP na concentração de $10^{-4} \mathrm{M}$ foi $p<0,05$ e entre o controle e o que recebeu 5 $x 10^{-5} \mathrm{M}$ de $\mathrm{p}<0,08$. 
VEGA, H.; NADER, H.; DIETRICH, C. P.; BUFFOLO, E. - Diminuição do sangramento pós-operatório produzido pela heparina, após aplicação tópica de adenosina trifosfato (ATP) em cirúrgia cardiaca com circulação extracorpórea. Rev. Bras. Cir. Cardiovasc., 8 (2):91-96, 1993.

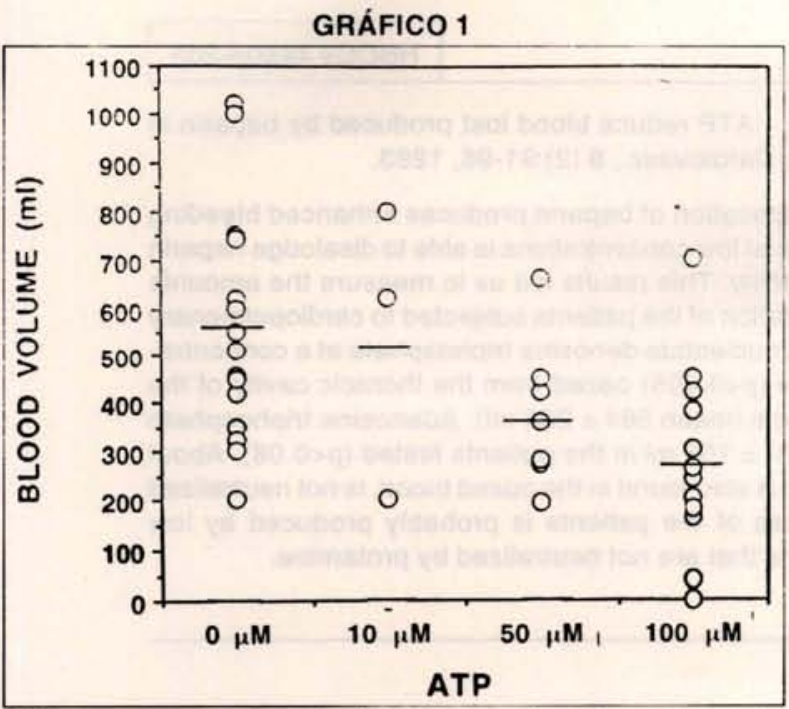

Efeito da aplicaçāo tópica de ATP sobre o volume de sangramento pós-operatório de pacientes submetidos a cirurgia cardiaca com auxílio da circulaçāo extracorpórea. Antes de fechar a cavidade torácica, o mediastino foi lavado com $500 \mathrm{ml}$ de solução fisiológica e diferentes concentrações de ATP, como indicado no Gráfico. O volume de sangue dos drenos da cavidade torácica dirigem-se a 2 frascos com $200 \mathrm{ml}$ de solução salina cada.

Esses dados sugeriram a possibilidade de uma curva dose-resposta ao uso do ATP, como demonstrado no Gráfico 2. É possível que concentrações mais elevadas de ATP reduzam ainda mais o sangramento pós-operatório desses pacientes.

Não foram observadas diferenças estatisticamente significativas entre o grupo que recebeu 100 $\mathrm{mg}$ de sulfato de protamina e o grupo controle.

\section{COMENTÁRIOS}

Nossos resultados são indicativos de que a protamina é incapaz de neutralizar completamente a heparina circulante em pacientes submetidos a cirurgia com auxílio da circulação extracorpórea. Tal fato já havia sido observado por HARENBERG et alii ${ }^{6}$, que verificaram que a protamina era incapaz de neutralizar a heparina de baixo peso molecular. Como já mencionamos anteriormente, é possível que tal heparina de baixo peso molecular seja responsável pelo sangramento de pequenos vasos e capilares ${ }^{11}$. Esses dados também concordam com os de IRELAND et alii ${ }^{7}$, que observaram san-

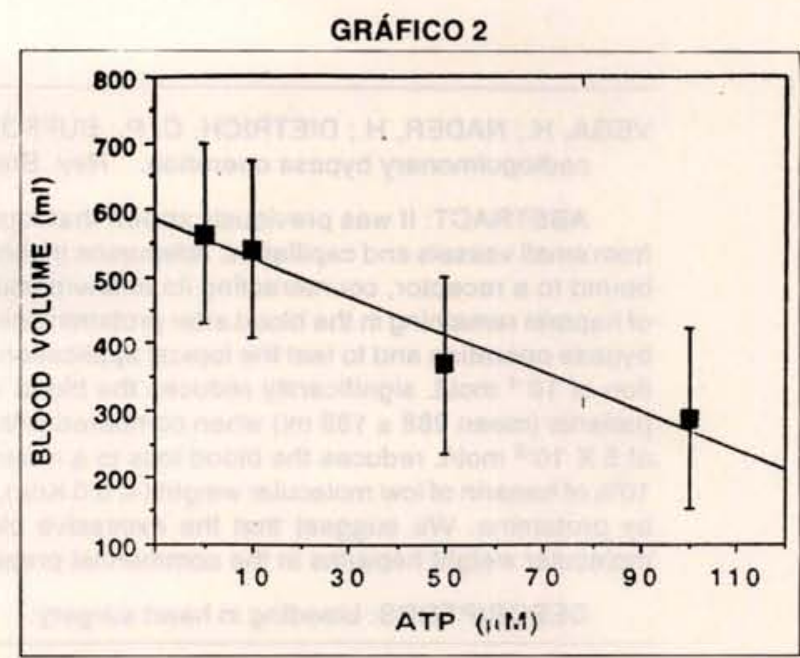

Efeito dose-dependente do APT em reduzir a perda sangúinea de pacientes submetidos a cirurgia cardiaca com auxilio da circulaçāo extracorpórea. Essa é a média de perda sangũínea dos pacientes utilizando diferentes concentraçōes de ATP (Gráfico 1). As barras verticais representam o desvio padrão de cada ponto.

gramento excessivo em 4 pacientes operados com uso da circulação extracorpórea, nos quais se utilizou heparina de baixo peso molecular. Concordam, também, com nossos dados experimentais, onde a heparina de baixo peso molecular foi 4 vezes mais potente em produzir hemorragia, quando comparada às heparinas comerciais ${ }^{4}$.

Confirmamos, neste estudo, o que já haviamos observado em nossos modelos experimentais 2, 4, 11 , ou seja, que o ATP é capaz de reduzir significativamente o sangramento produzido durante operações com uso da circulação extracorpórea e que esta ação parece seguir uma curva dose-resposta. É possível que, em concentrações maiores, tais como $10^{-3} \mathrm{M}$ de ATP, a redução do sangramento poderia ser ainda maior. Uma das vantagens da utilização do ATP topicamente seria a de reduzir a necessidade de transfusões sangüíneas, bem como - número de reoperaçōes onde se observa sangramento difuso do mediastino.

O ATP é rapidamente degradado pelas ATPases presentes nos tecidos lesados. Possivelmente, o uso de derivados de ATP, que agem nos receptores de células musculares lisas e sejam resistentes às ATPases possam ser mais efetivos do que o próprio ATP no controle do sangramento desses pacientes. 
VEGA, H.; NADER, H.; DIETRICH, C. P.; BUFFOLO, E. - Diminuição do sangramento pós-operatório produzido pela heparina, após aplicação tópica de adenosina trifosfato (ATP) em cirúrgia cardiaca com circulação extracorpórea. Rev. Bras. Cir. Cardiovasc., 8 (2):91-96, 1993.

RBCCV 44205-203

VEGA, H.; NADER, H.; DIETRICH, C. P.; BUFFOLO, E. - ATP reduce blood lost produced by heparin in cadiopulmonary bypass operation. Rev. Bras. Cir. Cardiovasc., 8 (2):91-96, 1993.

ABSTRACT: It was previously shown that topical application of heparin produces enhanced bleeding from small vesseis and capillaries. Adenosine triphosphate at low concentrations is able to disalodge heparin bound to a receptor, counteracting its antihemostatic activity. This results led us to measure the amounts of heparin remaining in the blood after protamine neutralization of the patients subjected to cardiopulmonary bypass operation and to test the topical application of the nucleotide denosine triphosphate at a concentration of $10^{-4} \mathrm{~mol} / \mathrm{L}$ significantly reduces the blood volume $(p<0,005)$ oozed from the thoracic cavity of the patients (mean $288 \pm 188 \mathrm{ml}$ ) when compared with controls (mean $564 \pm 288 \mathrm{ml}$ ). Adenosine triphosphate at $5 \times 10^{-5} \mathrm{~mol} / \mathrm{L}$ reduces the blood loss to a mean of $370 \pm 155 \mathrm{ml}$ in the patients tested $(p<0.08)$. About $10 \%$ of heparin of low molecular weight $(\leqslant 6.0 \mathrm{Kda})$, which is also found in the oozed blood, is not neutralized by protamine. We suggest that the excessive blood loss of the patients is probably produced by low molecular weight heparins in the commercial preparations that are not neutralized by protamine.

DESCRIPTORS: bleeding in heart surgery.

\section{REFERÊNCIAS BIBLIOGRÁFICAS}

1 CRUZ, W.O. - The significance of a smooth muscle component in hemostasis. Proc. Soc. Exp. Biol. Med., 119: 876-883, 1965.

2 CRUZ, W. O. \& DIETRICH, C. P. - Antihemostatic effect of heparin counteracted by adenosine triphosphate. Proc. Soc. Exp. Biol. Med., 126: 420-426, 1967.

3 DIETRICH, C. P. \& NADER, H. B. - Fractionation and properties of four heparitin sulfates from beef lung tissue: isolation and characterization of a homogeneous species of heparitin sulfate. Biochem. Biophys. Acta, 345: 34-44, 1974.

4 DIETRICH, C. P.; TERSARIOL, I. L. S.; SILVA, R. G.; BIANCHINI P.; NADER H. B. - Dependence of the C-6 sulfate to the glucosamine moiety and 1-4 glycosidic linkage of heparin disacharides for production of hemorrhage: reversal of the antihemostatic activity of heparin and their fragments by adenosine triphosphate and myosin. Sem. Thrombosis Hemat., 17: 65-73, 1991.

FEDAN, J.S.; HOGABOOM, G. K.; O'DONNEL, J. P. Further comparison of contractions of the smooth muscle of the guinea pig isolated vs. diferent induced by ATP and related analogs. Eur. J. Pharmacol., 120: 279-291, 1986.
6 HARENBERG, J.; GNASSSO, A.; VRIES J. X.; ZIMMERMAN, R.; AUGUSTIN, J. - Inhibition of low molecular weight heparin by protamine chloride in vivo. Thrombosis Res., 38: 11-23, 1985.

7 IRELAND, H.; RYLANCE, P. B.; KESTEVEN, P. - Heparin as an anticoagulant during extracorporeal circulation. In: LANE, D. A. \& LINDAHL, U. (eds.) London, Edward Arnold Publishers, 1989. p. 549-574.

8 NADER, H. B. \& DIETRICH, C. P. - Effect of heparitin sulfate fractions on hemostasis. Proc. Soc. Exp. Biol. Med., 146: 504-508, 1974.

9 NADER, H.B.; McDUFFIE, N. M.; DIETRICH, C. P. Heparin fractionation by electrophocusing: presence of 21 components of different molecular weights. Biochem. Biophys. Res. Commun., 57: 488-493, 1974.

10 NADER, H. B.; DIETRICH, C. P.; BUONASSISI, V.; COLBURN, P. - Heparin sequences in the heparin sulfate chains of endothelial cell proteoglycan. Proc. Nat. Acad. Sci. (USA), 84: 3565-3569, 1987.

11 NADER, H. B.; TERSARIOL, I. L. S.; DIETRICH, C. P. - Antihemostatic activity of heparin disaccharides and oligosacharides obtained by chemical and enzymatic fragmentation: reversal of the hemorrhagic activity by ATP and myosin. Thrombosis Res., 54: 207. $214,1989$. 